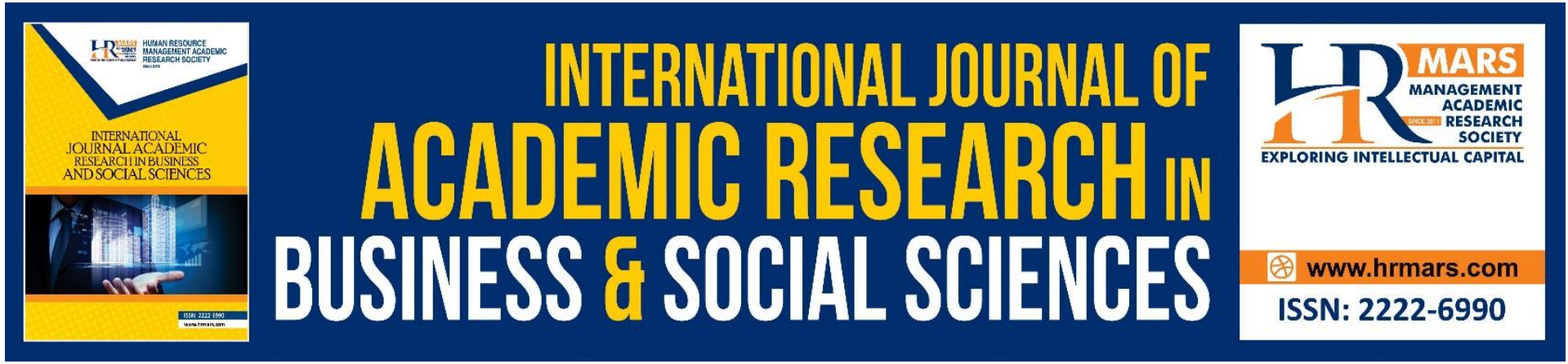

\title{
The Impacts of Transformational Leadership and Employee Reactions on Individual Work Performance: Exploring Individual Adaptability as a Moderator
}

\author{
Albert Apoi, Hamrila Binti Abdul Latip and Dayang Affizzah Binti Awang \\ Marikan
}

To Link this Article: http://dx.doi.org/10.6007/IJARBSS/v11-i9/10993

DOI:10.6007/IJARBSS/v11-i9/10993

Received: 06 July 2021, Revised: 24 July 2021, Accepted: 20 August 2021

Published Online: 11 September 2021

In-Text Citation: (Apoi et al., 2021)

To Cite this Article: Apoi, A., Latip, H. B. A., \& Marikan, D. A. B. A. (2021). The Impacts of Transformational Leadership and Employee Reactions on Individual Work Performance: Exploring Individual Adaptability as a Moderator. International Journal of Academic Research in Business and Social Sciences, 11(9), 205-233.

Copyright: @ 2021 The Author(s)

Published by Human Resource Management Academic Research Society (www.hrmars.com)

This article is published under the Creative Commons Attribution (CC BY 4.0) license. Anyone may reproduce, distribute, translate and create derivative works of this article (for both commercial and non-commercial purposes), subject to full attribution to the original publication and authors. The full terms of this license may be seen at: http://creativecommons.org/licences/by/4.0/legalcode

Vol. 11, No. 9, 2021, Pg. 216 - 233

Full Terms \& Conditions of access and use can be found at http://hrmars.com/index.php/pages/detail/publication-ethics 


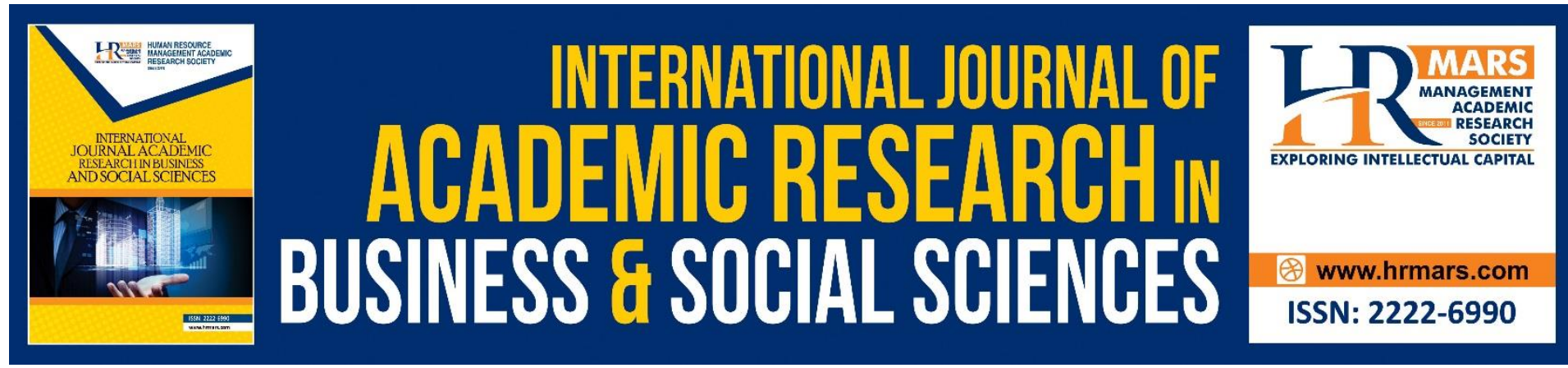

\title{
The Impacts of Transformational Leadership and Employee Reactions on Individual Work Performance: Exploring Individual Adaptability as a Moderator
}

\author{
Albert Apoi, Hamrila Binti Abdul Latip and Dayang Affizzah Binti \\ Awang Marikan \\ Faculty of Economics and Business, Universiti Malaysia Sarawak, 94300 Kota Samarahan, \\ Sarawak Malaysia. \\ Email: arbalbert@yahoo.com, alhamrila@unimas.my, amdaffizah@unimas.my
}

\begin{abstract}
This research emphasized the significance of individual adaptability that plays the moderator role in the relationships of transformational leadership and employee reactions with individual work performance within the Malaysian oil and gas industry. The study respondents were employees of an oil and gas company operating in East and West Malaysia, specifically in the upstream segment. The respondents self-administered the questionnaire provided at their flexibility. The Structural Equation Modelling (SEM) in IBM-SPSS-AMOS 24.0 software was utilized to analyze and assess the inter-relationships of the study constructs. Individual adaptability was found to moderate the relationships of individual work performance with transformational leadership and employee reactions. The study findings stressed the significance of individual adaptability in boosting work performance, particularly in the oil and gas industry. Research on the moderating role of individual adaptability in the relationships of individual work performance with transformational leadership and employee reactions is limited, specifically in the Malaysian oil and gas industry. Creative, innovative, collaborative, and analytical skills are fundamental in this industry to be more competitive and generate new ideas, products, and procedures.
\end{abstract}

Keywords: Individual Adaptability, Individual Work Performance, Job Satisfaction, Organizational Citizenship Behavior, Organizational Commitment, Transformational Leadership

\section{Introduction}

Leadership effectiveness is vital in an organization as organizational failure may cause leadership issues if not handled tactfully. Employees usually leave an organization due to lousy leadership rather than the organization itself. Thus, the leadership effectiveness model should be frequently revisited to adapt to the current work environment. Individual adaptability is becoming progressively crucial in motivating employees' work performances in organizations due to the Industrial Revolution 4.0 (IR 4.0) impact that triggered a change in 
the overall capital management landscape. Organizations today increasingly rely on technology for business operations forcing employees to perform tasks irreplaceable by technology. Nevertheless, the developed individual adaptability constructs are not allinclusive to assess individual adaptation to a new environment. In addition, the constructs are restricted to uncertainties, interpersonal, cultural, and job stress contexts. Thus, the current research is compelled to integrate skills irreplaceable by technology, particularly analytical, collaborative, creative, and innovative skills, which have not been emphasized based on Polyhart and Beliese's (2006) definition of individual adaptability.

The integrated skills align with Lau (2017), who highlighted that the current working environment requires adaptable and creative employees, while immense teamwork is crucial for developing the needed skills. Additionally, previous studies on leadership effectiveness lack a comprehensive employee reactions perspective, namely psychological, behavioral and emotional, in a single study. The comprehensive perspective can be observed from employee's organizational commitment, organizational citizenship behavior, and job satisfaction. An ideal leadership effectiveness model should include these perspectives. The primary study objectives are as follows:

- To evaluate the moderating effect of individual adaptability in the relationship between transformational leadership, employee reactions, and individual work performance

- To propose a leadership effectiveness model for individual work performance

The comprehensive employee motivation perspective can be explained by the cognitive theory called the expectancy theory of motivation that inclines toward a personcentric approach. This theory concentrates on how an individual comprehends the performance process. The 'expectancy' aspect of the expectancy theory plays a critical part when leadership affects the employees' psychological state. The effect can be observed in the employees' commitment levels. A committed employee will display a belief performance (instrumentality) that reflects in the employee's behavior. Based on the expectancy theory, employees' perspectives on the performance process links performance to rewards. Subsequently, employees who appreciate rewards (valance) and obtain them due to excellent performance will be gratified for the reward. Hence, organizations can understand employee reactions better with this comprehensive perspective, which ultimately influences individual work performance.

\section{Significance of the Study}

Few researchers explored leadership in the context where organizations are under a challenging environment or in "times of stress" (Bass, 1985, p.xiv). Hence, the current study is one of the pioneer studies in the oil and gas industry, which is currently affected by the sharp decline in oil prices and the recent pandemic outbreak. The present study also serves a pioneer study to provide a comprehensive perspective of employee motivation that covers the psychological, behavioral, and emotional states of employees in a single study. These comprehensive perspectives of employee motivation can be explained by the cognitive theory called the expectancy theory of motivation, which is inclined towards the person-centric approach. This theory concentrates on how individuals perceive the performance process. From the methodological perspective, this research contributes to the measurement instrument development for individual adaptability by incorporating skills in the measurement items. The four sub-constructs incorporated in individual adaptability are 
creative skills, innovative skills, collaborative skills, and analytical skills. The newly developed scales are proven reliable and valid and can be used for future research. The study feasibility can be extended to the educational level by inculcating the right culture through suitable curriculum activities and sports. Besides, the study is also practical at the organizational level for organization development purposes in the reward system area, promoting working arrangement flexibility and providing a conducive working environment.

\section{Literature Review}

\section{Transformational Leadership}

The most favored and adapted leadership style across various nations, cultural contexts, situations, and industries worldwide is transformational leadership (Ozaralli, 2003; Brian \& Lewis, 2004; Xirasagar, 2008; Ivey \& Kline, 2010; Ling et al., 2011; Jogulu \& Ferkins, 2012; Dai et al., 2013; Abd Rahman et al., 2013; Hardy, 2014; Dg Kamisah \& Syed, 2015; Katou, 2015). Transformational leadership is commonly accepted as employees are prompted to put extra effort by improving workplace morale and encouraging them to assist employees and organizations positively. Contrarily, Sarros and Santora (2001) emphasized that financial rewards and acknowledgment to employees are provided in exchange for delivering expected performance in transactional leadership. Nonetheless, a leadership style may not fit all contexts due to complexities in the work environment, distinctive cultural settings, and distinct policies and practices in various nations.

Thus, the initiative to combine transformational and transactional leadership styles transpires to reap maximum advantages for employees and organizations (Brian \& Lewis, 2004; Judge \& Piccolo, 2004; Dai et al., 2013) and achieve leadership effectiveness concurrently (Evans \& Lindsay, 2011). Nonetheless, Erkutlu (2008) asserted that transformational leadership behaviors must be displayed in the swiftly transforming current business environment. The nature of a successful relationship between leaders and followers decisively substantiates leadership. Consequently, the current research divulges into the implication of transformational leadership behaviors and the effects rather than transactional leadership to contribute additional evidence to the available literature in this context.

\section{Employee Reactions}

The current research utilized three employee reactions classifications: organizational commitment, organizational citizenship behavior, and job satisfaction, out of Katou's (2015) four categories, including motivation. The three constructs were selected due to extensive adoption in leadership effectiveness studies worldwide and encompass wide employee responses from thorough psychology, behavior, and emotional perspectives. Initially, organizational commitment comprises a psychological state rather than attitudinal and behavioral states and includes three essential components delineated by Meyer and Allen (1991). The components include affective, continuance, and normative commitment that delve into the employees' desire, need, and obligation in the organizations.

Next, organizational citizenship behavior examines the employees who work voluntarily exceeding the work role organizations require or call of duty (Dai et al., 2013; Kreitner \& Kinicki, 2013). Organizational citizenship behavior commonly boosts organizations but is frequently overlooked in reward systems (Organ, 1988). Lastly, job satisfaction is portrayed as an attitude rather than a behavior. Job satisfaction also imitates an individual's feeling on something or a positive mind state, involving the emotional impact of work experiences and employees' appraisal (Robbins \& Coulter, 2005; Nelson \& Quick, 2013). Job 
satisfaction is often utilized as a leadership effectiveness indicator that reflects organizational performance. Hence, the comprehensive perspective from the employee reactions inspires the present study to incorporate employee reactions as measurement scales.

\section{Individual Adaptability}

Fast transformation in policies, procedures, mergers of companies, and the complications of specified concerns require individuals to react to vague complications (Chan, 2014). The concept of individual adaptability is developed from uncertainties in the environment and correlates with the working environment. Individual adaptability commonly denotes positive motivational orientation toward transforming oneself (Wang et al., 2017) and is correlated with individual adaptation to uncertainties, culture, and interpersonal situations. Nevertheless, Polyhart and Bliese (2006) suggested that adaptability can also be outspread to employees' skills in the work domain. Employee adaptability studies concerning the vital skills in familiarizing to the new IR 4.0 age are scarce. Therefore, the present study aimed to study the four skills as the new individual adaptability measurements: analytical, collaborative, creative, and innovative skills.

\section{Creative Skills}

Creativity implies skills irreplicable by artificial intelligence. Employees are frequently urged to 'think outside the box' and yield new ideas for new goods or answers for open-ended problems. Thus, employees must exercise creative skills as creativity is deemed crucial for companies to survive in the vibrant business environment. Creativity is also denoted as producing novel and compelling thoughts to improvise available processes, services, products, and operating procedures, requiring employees to possess in-depth knowledge in subject matters (Moirana et al., 2020). Creativity is incorporated into multidisciplinary fields that evaluate management, socio-cultural and psychological viewpoints unitedly per current trends. Thus, the latest growth trends displayed that creativity is gradually crucial for employees and places creativity as a crucial aspect of individual adaptability aspect.

\section{Innovative Skills}

Creativity frequently generates innovative thoughts being included in every process of innovation adoption (Dino, 2015; Oddane, 2015; Tang \& Werner, 2017). Nevertheless, ideas that are innovative might be beneficial to organizations but exert mixed effects on the employees. For example, Janssen and Nico (2004) doubted that innovative employees tend to experience impediments from colleagues attempting to hinder innovative transformation. Additionally, innovative ideas might cause uncertainties and insecurities among employees. Thus, persuading employees about innovation benefits is tricky but also demanding. Moirano et al. (2020) highlighted that innovation commonly includes creative ideas generation and implementation. Hence, innovative skills or innovation were deemed another meaningful individual adaptability aspect in the current research.

\section{Collaborative Skills}

Collaboration is debated to affect creativity as the capability to maximize the viability, desirability, and feasibility for developing services, technologies, and products for particular objectivities. However, creativity is primarily natural and results in innovation (Kuo, Tseng, \& Yang, 2019). The capability of collaboration skills in dealing with a broad perspective range, investigating issues in an expansive setting and evaluating the complications of an issue 
providing the precise blend for this aspect to function as an individual adaptability dimension. In addition, Leana et al. (2009) asserted that collaboration is correlated with higher commitment and satisfaction among employees. Thus, another individual adaptability element in this research is collaborative skills.

\section{Analytical Skills}

The IR4.0 has considerably transformed the working environment, developing a dynamic environment and challenges the present process to transfer to the subsequent level. Similarly, organizations persistently face upcoming issues and unexpected situations requiring new and feasible solutions to be discovered by their employees. Thus, analytical skills can be outlined as the rational thinking style or momentary thinking orientation (Novak \& Donna, 2009). Furthermore, the analytical skills attributes tend to be process-oriented and involve decision-making according to reasons and evaluating the cause and effect, making them irreplicable by artificial intelligence. Thus, the analytical skill was chosen as an individual adaptability element in the current study. The IR4.0 impact has transformed the workplace landscape in workforce management. Thus, organizations need to revolutionize their workforce to be more agile, flexible, and adaptive to changes happening in their surroundings. Besides, considerable interest is evident in individual adaptability at the workplace over the years but concentrates on extraneous contexts, such as culture and unfamiliar settings (e.g., Zorzie, 2012; Bartone et al., 2018; Hua et al., 2018).

\section{Individual Work Performance}

Performance is measurable according to groups' progress, preparedness, performance, and survival, inclusive of their mutual capacity in managing crises (Erkutlu, 2008). In addition, Md. Zabid et al. (2002) mentioned that performance could be assessed according to financial status, employee commitment, and satisfaction. As the current research delves into individual-level performance and focuses on actions or behaviors in preference to the results, individual performance will be measured following the three task performance elements, contextual performance and counterproductive behavior at work. Based on work and organizational psychology, individual work performance denotes meaningful activities or behaviors for organizational aims (Koopmans et al., 2011). In summary, individual work performance assesses the controllable behavior, excluding external behavior inhibited by the environment, and supplements the construct appropriateness (Ratundo \& Sackett, 2002).

\section{Hypotheses Development}

Researchers expanded studies on transformational leadership influence to observe the outcome that impacts individual and organizational performance (Steyrer et al., 2008; Munchiri et al., 2012). As per prior literature, the leadership variables, employee reactions, and individual work performance were positively interrelated (Nguni et al., 2006; Han et al., 2016). For instance, Braun et al. (2013) exhibited a positive relationship between transformational leadership and team performance, while Griffith (2004) discovered that transformational leadership had an indirect effect on school performance. Hence, the present study proposed the following first hypothesis:

Hypothesis 1: Transformational leadership is positively related to individual work performance. 
Apoi and Latip (2019) concluded that leadership outcomes comprise two stages of transformational leadership behaviors: intermediate and performance outcomes. Intermediate outcomes are characterized as employee reactions, whereas performance outcomes are characterized as individual work performance. Besides, Edwards et al. (2008), Kinicki and Fugate (2012), and Babalola (2016) proved that job satisfaction positively influences performance. Hence, the following hypothesis was formed:

Hypothesis 2: Employee reactions are positively related to individual work performance.

Previous studies showed that adaptability influences individual performance (e.g., Vaughn, 2011; Zhou \& Lin, 2016; Stachelek, 2018). A recent study by Ingusci (2019) also indicated that individual adaptability could be a moderator in the working domain. Therefore, based on the evidence that individual adaptability moderates the relationship between transformational leadership and individual work performance, the third hypothesis was proposed as the following:

Hypothesis 3: Individual adaptability moderates the direct effect of transformational leadership on individual work performance.

Besides, the present study predicts the potential of individual adaptability in moderating the relationship between employee reactions and individual work performance. Hence, this study formed the fourth hypothesis as follows:

Hypothesis 4: Individual adaptability moderates the direct effect of employee reactions on individual work performance.

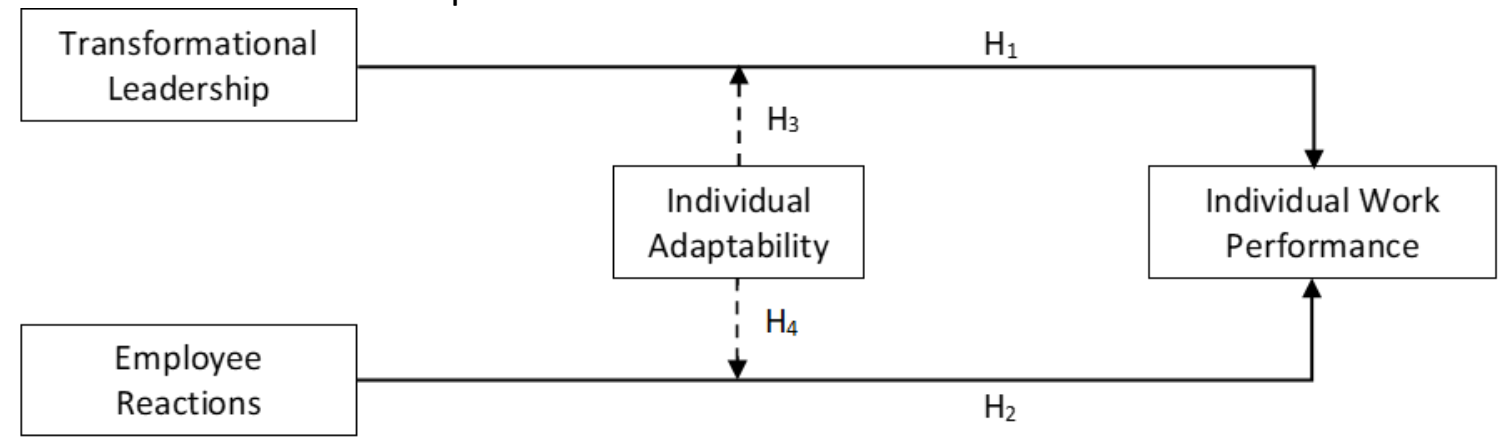

Figure 1: The framework of the study

\section{Method}

The current research is based on the positivism paradigm and utilized a quantitative approach in assessing the inter-relationship between the constructs (Refer to Figure 1). Thus, the SEM method from IBM-SPSS-AMOS 24.0 software was employed.

\section{Respondents}

The target population was the Malaysian oil and gas industry. The sampling frame consists of employees working in the upstream oil and gas industry segment on a contract or non-contract basis. Respondents were required to include their demographic details such as age, race, job position, educational background, experience, employment length in the organization, and employment status.

Sampling Procedures 
The multistage sampling approach encompasses cluster, stratified, and simple random sampling techniques was utilized in the present study. The cluster sampling technique is preferred due to its simplicity and convenience in covering East and West Malaysia. Nevertheless, the researcher employed the stratified sampling method deemed suitable for SEM, as Awang (2012) indicated. In addition, this method produces a more accurate and unbiased estimator besides ensuring sufficient sample size within the target population subgroups (Bryman, 2015). After determining the stratified sampling, the researcher applied the simple random sampling technique to choose respondents from the subgroups. This method ensures that subgroups within the population have an equal probability of being chosen (Cochran, 1953; Hansen et al., 1953; McKay et al., 2000). Conversely, Kline (2016) illustrated that 30 to 460 cases are the minimum sample sizes for models in which the number of factors is one to three with three to eight indicators for each factor.

\section{Sample Size}

The researcher chose a random sample involving 400 respondents from the sampling frame through multistage sampling as the respondents were selected to fulfill specific criteria. Questionnaires were distributed via the postal, drop-and-collect method and an electronic survey. The chosen respondents were allowed to self-administer the questionnaires at their convenience without distress or worry. The first data collection wave yielded a return of 76 questionnaires, while the second wave yielded another 136 questionnaires, totaling 212 and $53.0 \%$ return rate. After the data cleaning process to remove incomplete questionnaires, only 204 questionnaires were utilized for data analysis.

\section{Measurement of Construct}

Transformational leadership adapted and utilized Bass and Avolio's Multifactor Leadership Questionnaire (MLQ) as the instrument to measure leadership behaviors and consisted of 14 items. Employee reactions used the three instruments from Organizational Commitment Questionnaires (OCQ) (Porter et al., 1974), Organizational Citizenship Behavior Scale (OCBS) adopted from Podsakoff et al.'s (1990) original work, and Job Satisfaction Survey (JSS). Conversely, work performance utilized the Individual Work Performance Questionnaire (IWPQ) instrument adopted from Koopman et al. (2012).

Additionally, individual adaptability as the moderator was self-constructed and divided into four categories, namely creative, analytical, innovative, and collaborative skills adapted from Novak and Donna (2009), Zhang and Kathryn (2010), Janssen and Nico (2004), and Leana et al. (2009). Each item under the mediating variable was selected from various sources and combined under individual adaptability. A statement with a ten-point Likert scale labeled from 1 = Strongly Disagree to $10=$ Strongly Agree represented a total of 64 items.

\section{Research Design}

The current research is based on a correlational research design that takes place in a community's natural context with minimal researcher interference. Data collection was undertaken after developing the theoretical framework, and the data was analyzed to conclude the findings. Cooper and Schindler (2008) highlighted that a correlational research design is structured with clear hypotheses to identify the relationships between variables. Hence, the relationships between the independent, dependent, and moderating variables were identified in this research. 
This research also simultaneously utilized a cross-sectional design by collecting data in unison and at a particular time (Cooper \& Schindler, 2008). The researcher also employed probability sampling and efficiently used a survey method to group associations involving sociological variables and constructs such as beliefs, attitudes, opinions, and preferences (Salkind, 2006). Cooper and Schindler (2008) indicated that multistage sampling occurs when the respondents are selected to fulfill specific criteria.

\section{Statistical Procedure}

The IBM-AMOS software was utilized to investigate statistical relationships of items in each construct and between the constructs. Among the advantages of utilizing IBM-AMOS to develop SEM are:

i. It presents the model graphically rather than textually (Hoyle, 2012).

ii. It reduces measurement errors by running confirmatory factor analysis (CFA).

iii. It deals with the multicollinearity problem among independent constructs.

iv. It assesses the fitness of the measurement and structural models.

v. It analyses the effects of moderating variables.

vi. It analyses the first-order and second-order constructs in the structural model.

vii.

Three main procedures were conducted for the data analysis: exploratory factor analysis (EFA), CFA, and SEM.

\section{Results}

The Confirmatory Factor Analysis (CFA)

The CFA is required to confirm the validity of the latent constructs encompassed in a measurement model. Besides, the CFA also measures construct, convergent, and discriminant validity (DV). Although construct reliability is measured by composite reliability (CR), the researcher also applied pooled CFA (Refer to Figure 2 and Figure 3) due to its efficiency, thoroughness, and free from any model identification issues, particularly in several cases, where certain constructs include not more than four measuring items (Awang et al., 2015a; Kashif et al., 2016). The CFA findings generated the following fitness indexes: The fitness indexes that denote construct validity is Root Mean Square of Error Approximation (RMSEA) $=0.055$, Comparative Fit Index $(\mathrm{CFI})=0.929$, and $\mathrm{ChiSq} / \mathrm{df}=1.637$.

All fitness indexes have reached the appropriate level, and the measurement model has achieved construct validity. Similarly, the CR measures for construct reliability and the average variance extracted ( $A V E$ ) for convergent validity were required. CR requires a threshold value exceeding 0.6, whereas AVE requires a threshold value greater than 0.5 (Fornell \& Larcker, 1981). Table 1 demonstrates that CR and AVE surpassed the threshold values of 0.6 and 0.5 , respectively. Thus, the values showed the convergent validity and CR of the major models (Awang, 2014; 2015a). 
Table 1: Discriminant validity, construct reliability, and average variance extracted of all constructs

\begin{tabular}{lll|lll}
\hline & $\begin{array}{l}\text { Average } \\
\text { Variance } \\
\text { Extracted } \\
\text { (AVE) }\end{array}$ & $\begin{array}{l}\text { Construct } \\
\text { Reliability } \\
\text { (CR) }\end{array}$ & $\begin{array}{l}\text { Individual } \\
\text { Work } \\
\text { Performance }\end{array}$ & $\begin{array}{l}\text { Employee Transformational } \\
\text { Reactions Leadership }\end{array}$ \\
\hline $\begin{array}{l}\text { Individual Work } \\
\text { Performance }\end{array}$ & 0.596 & 0.812 & $\mathbf{0 . 7 7 2}$ & & \\
\hline $\begin{array}{l}\text { Employee } \\
\text { Reactions }\end{array}$ & 0.871 & 0.953 & 0.640 & $\mathbf{0 . 9 3 3}$ & \\
\hline $\begin{array}{l}\text { Transformational } \\
\text { Leadership }\end{array}$ & 0.775 & 0.922 & 0.630 & 0.430 & $\mathbf{0 . 8 8 0}$ \\
\hline
\end{tabular}

The researcher must assess the DV to ensure no redundancy among constructs in the final CFA steps. The DV index summary in Table 1, represented by bolded diagonal values, denotes the constructs' AVE square root values, whereas other values indicate the connection between the constructs. The DV for all the constructs was attained as the diagonal values exceed other values represented in the respective columns and rows (Awang et al., 2015; 2018; Shkeer and Awang, 2019b).

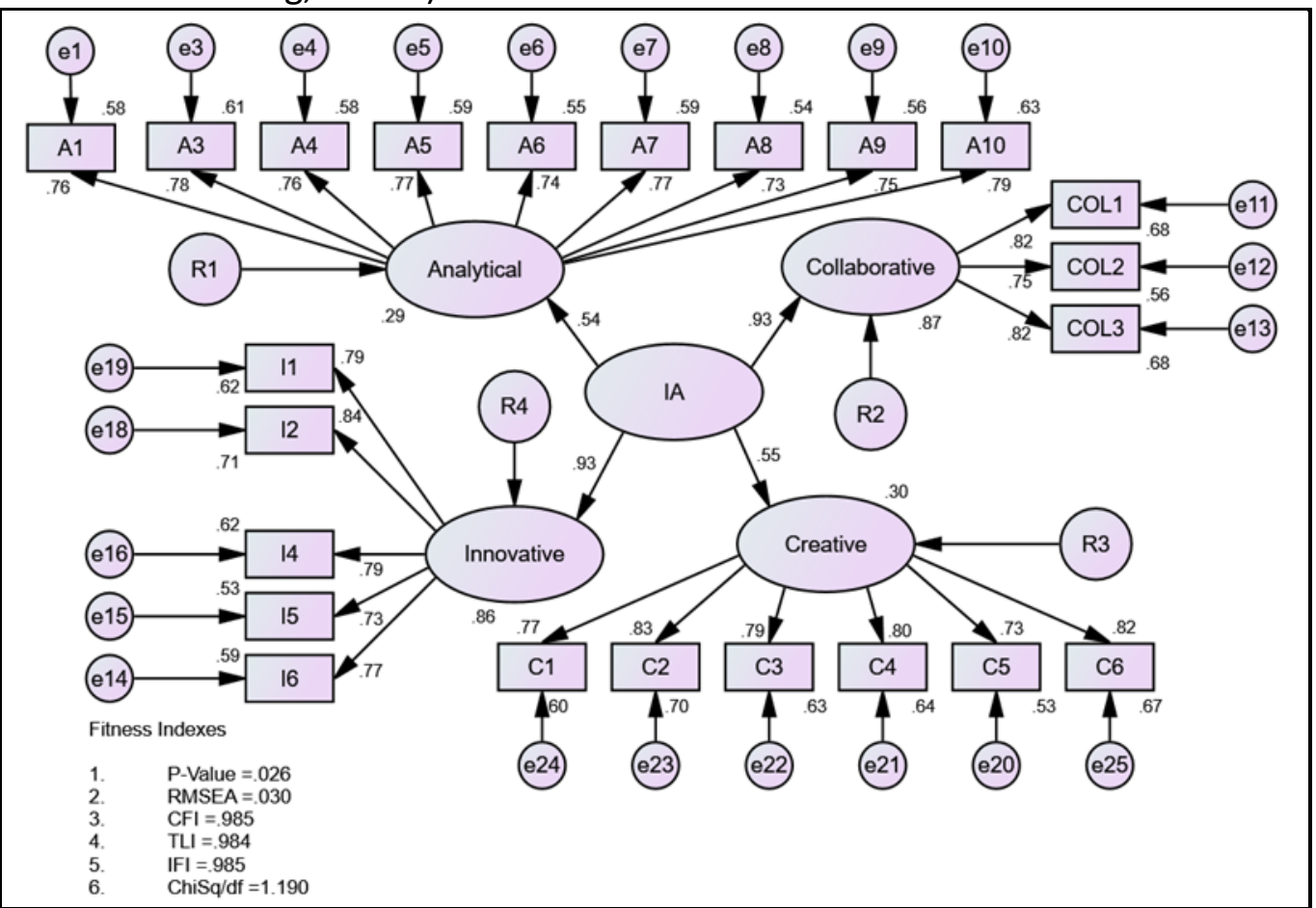

Figure 2: The pooled confirmatory factor analysis (CFA) for the moderating construct 


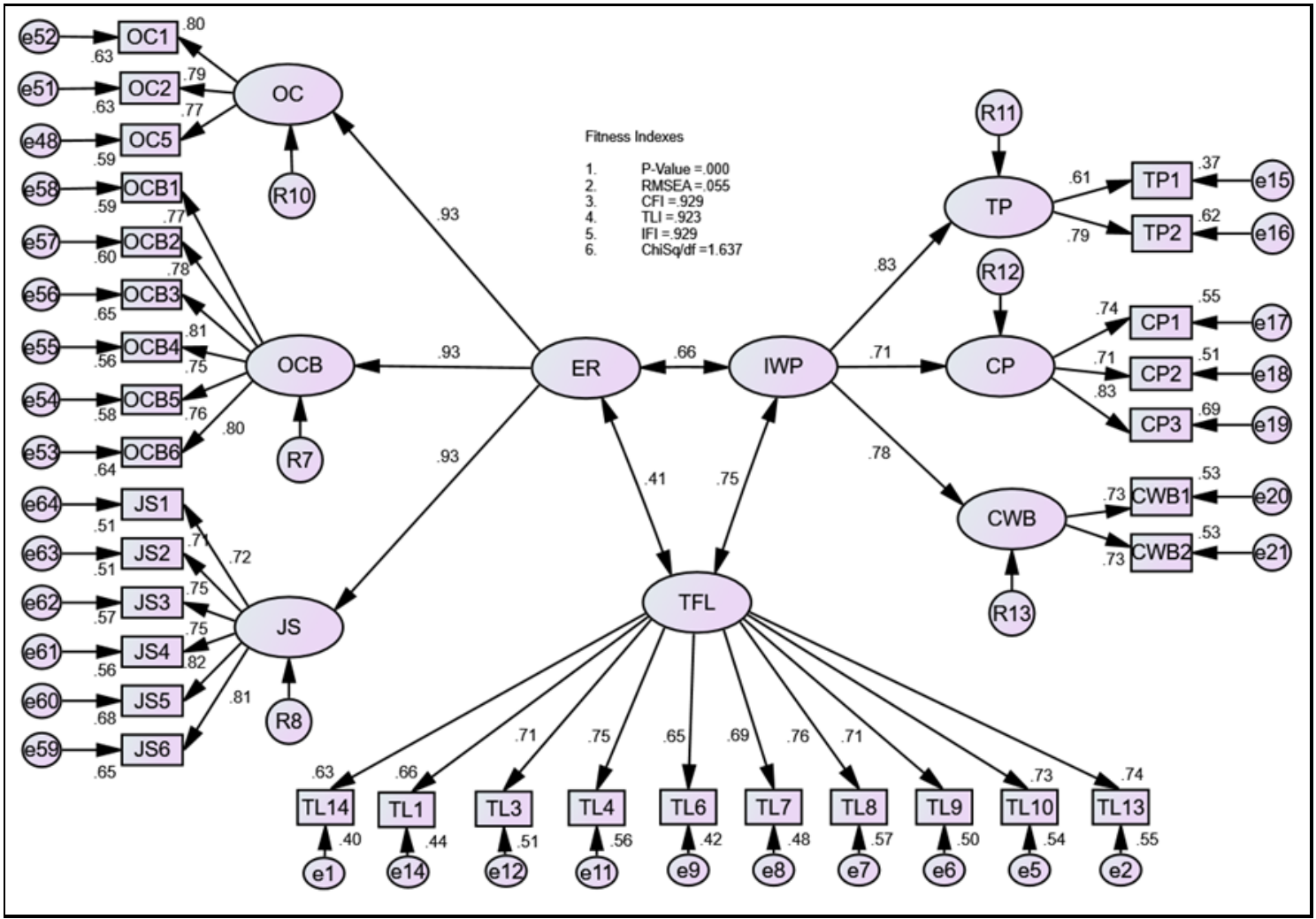

Figure 3: Pooled confirmatory factor analysis (CFA)

\section{Normality Assessment}

The normality assessment is crucial before the SEM, whereas the normality distribution of the dataset is examined utilizing the skewness and kurtosis value for each item. Hair et al. (2014) explained that kurtosis measures the extent of distribution peakness. The analysis result was normal because the acceptance value ranged from -3 to +3 kurtosis value. In addition, the findings exhibited that the skewness of the items is between the CR values of -2.059 and 1.406. The kurtosis estimations were between -1.555 and 2.141. Both measures denoted that the data correlates with normality distribution and fulfill the supposition for utilizing parametric statistical analysis (Hair et al., 2014; Awang et al., 2018). Furthermore, the kurtosis CR value below 50 is accepted (Hair, 2010). The response pattern in this study displayed a normal distribution as skewness and kurtosis recorded values near zero. Therefore, the researcher could proceed further with the SEM analysis.

\section{Structural Equation Modelling (SEM)}

The researcher subsequently modeled the variables into the structural analysis based on the research model in Figure 4 after addressing the validity, reliability, and multidimensionality issues of the latent variables. In general, SEM necessitates 200 samples as described in AMOS (Bagozzi \& Yi, 1988; MacCallum et al., 1996; Hooper et al., 2008) and is contingent upon stringent assumptions, such as homoscedasticity, normality, and free of outliers to acquire enough output and prevent non-convergence estimates depicted by Anderson and Gerbing (1988) and Hoyle (1995). Thus, the condition was achieved to assure the path estimate validity through maximum likelihood.

Figure 4 illustrates the two exogenous constructs (transformational leadership and employee reactions) related to the endogenous construct (individual work performance). According to Arbuckle (1995), a single arrow representing the causal effect should start from 
the exogenous constructs to the endogenous construct to evaluate the relationships between constructs. The present study examined and reported the path estimates of all the hypothesized relationships in the causal model and the Squared Multiple Correlation $\left(R^{2}\right)$ of the dependent variable as a structural model in Figure 4.

The proposed model explains a significantly acceptable percentage of the variance in individual work performance with 83\%, as illustrated in Figure 4. Cohen (1988) expressed that the $\mathrm{R}^{2}$ value with more than $26 \%$ has a significant effect on the causal model. Thus, the structural model that measures the individual work performance level is deemed achievable and valid due to the significance of individual work performance research.

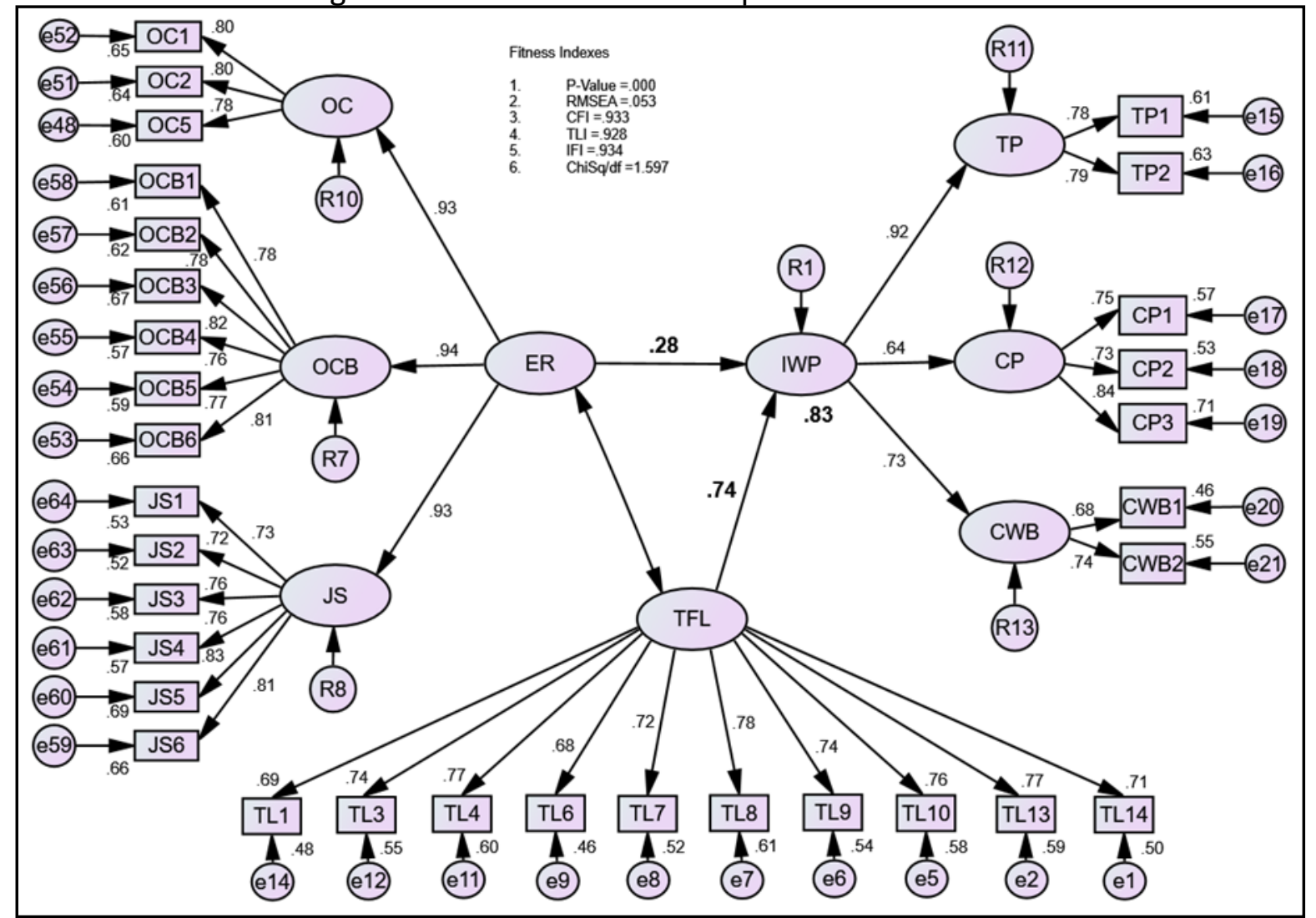

Figure 4: Standardized regression path coefficient

\section{Data Analysis}

The initial quantitative data analysis stage utilized the Statistical Package for Social Science (SPSS) software to determine the descriptive statistics and run the EFA. In contrast, the path analysis and CFA were undertaken by utilizing the IBM-AMOS software. The transformational leadership style had a direct positive and significant impact on individual work performance. Therefore, $\mathrm{H}_{1}$ is supported. In addition, employees' reactions also directly exerted a positive and significant impact on individual work performance, proving that $\mathrm{H}_{2}$ is supported. The present study also found that individual adaptability plays a moderator role in the relationship of transformational leadership and employee reactions with individual work performance. Thus, $\mathrm{H}_{3}$ and $\mathrm{H}_{4}$ are also supported. Table 2 depicts the summary of the overall findings.

The findings indicate that the moderating variable of individual adaptability strengthened the causal effects of transformational leadership and employee reactions on individual work performance. Thus, increased individual adaptability positively influences the relationships of transformational leadership and individual work performance and employee 
reactions and individual work performance. Hence, the moderation observed in both relationships is partial. The findings also imply that $83 \%$ of the individual work performance could be estimated through transformational leadership and employee reactions (Refer to Figure 4). Transformational leadership was found to influence individual work performance compared to employee reactions significantly. Thus, one unit increase in transformational leadership will result in a 0.801 unit increase in individual work performance.

Table 2: The regression path coefficient and its significance

\begin{tabular}{llllllll}
\hline Construct & Path & Construct & Estimate & S.E. & C.R. & p & Result \\
\hline $\begin{array}{l}\text { Individual Work } \\
\begin{array}{l}\text { Performance } \\
\text { <--- }\end{array}\end{array}$ & $\begin{array}{l}\text { Transformational } \\
\text { Leadership (TFL) }\end{array}$ & 0.801 & 0.098 & 8.180 & $* * *$ & Significant \\
\hline $\begin{array}{l}\text { Individual Work } \\
\text { Performance }\end{array}$ & $\begin{array}{l}\text { Employee Reactions } \\
\text { (ER) }\end{array}$ & 0.263 & 0.064 & 4.145 & $* * *$ & Significant \\
\hline $\begin{array}{l}\text { Individual Work } \\
\begin{array}{l}\text { Performance } \\
\text { <--- }\end{array}\end{array}$ & $\begin{array}{l}\text { TFL X Individual } \\
\text { Adaptability }\end{array}$ & 0.018 & 0.004 & 4.892 & $* * *$ & Significant \\
\hline $\begin{array}{l}\text { Individual Work } \\
\text { Performance }\end{array}$ & $\begin{array}{l}\text { ER X Individual } \\
\text { Adaptability }\end{array}$ & 0.060 & 0.006 & 9.884 & $* * *$ & Significant \\
\hline
\end{tabular}

*Note: Abbreviation = S.E. - Standard Error / C.R. - Critical Ratio

\section{Discussion}

The study findings indicated that four hypotheses developed had been supported. Transformational leadership and employee reactions are the factors that can influence individual work performance and positively influenced individual work performance in this study. Transformational leadership was found to be the strongest individual work performance predictor. Individual adaptability was found to moderate the relationships between transformational leadership and employee reactions with individual work performance. Thus, the validity and reliability of the new leadership effectiveness model are confirmed.

The repercussions of the current research supported the hypothesis that individual work performance is positively and significantly impacted by transformational leadership style. During crises, transformational leadership has been proven acceptable and preferred in Malaysian oil and gas companies and can increase individual work performance. Malaysian oil and gas companies' employees who have a higher employee commitment, citizenship behavior, and higher satisfaction generally displayed higher individual work performance. The employee reactions' impact supports the notion of the expectancy theory, where each individual performance is due to individual effort.

The findings supported the hypothesis that the direct effect of transformational leadership and employee reactions on individual work performance in Malaysian oil and gas companies is moderated by individual adaptability. Thus, the findings suggest the significance of the skill set in establishing a work culture that incites creativity in the work context. Furthermore, the skills are vital in effectively producing new processes or products for businesses to gain a competitive advantage.

Therefore, organizations must be unique and efficient from competitors in developing products or business processes to ensure their sustainability in the industry. Redundant jobs will be replaced by technology in organizations. Thus, organizations should groom their workforce to carry out jobs that technology cannot replicate, including the invention of new 
procedures or products. A model of new leadership effectiveness that integrates individual adaptability as the moderator role has been established and verified. The findings suggest the significance of the discussed skills in conceiving a work culture that integrates creativity into the work environment, contributes effectively to the production of new procedures and products for businesses to gain a competitive advantage.

Numerous limitations to the methodology were considered throughout the study, and procedural remedies during the pre-test were taken to minimize the issue. First, the common method variance was an issue in the research because the responses tend to overlap when data are obtained from single sources. Second, the data were collected during the Movement Control Order enforcement due to the recent pandemic outbreak. Hence, the responses to the statements could be different at the organizational level depending on the companies' effectiveness in dealing with the current issue. Future studies can extend the present study to industries directly impacted by technology and under stress due to high competition, such as the banking industry. Future researchers should explore the area where organizations are under stress due to high competition and changes in the economic landscape or leadership that provide the best platform for researchers to understand how organizations react or respond when required to change.

The findings provide fresh insights into other factors that influence and stimulate individual work performance in organizations. The increasing demand for employees to be more adaptive and proactive in organizations shows that the skill sets required today are different from the past requirements requiring employees to be loyal and committed to organizations. Changes occur in career or personal domains. Nevertheless, the primary issue is not the changes but how humans can adapt to the changes. Oil and gas is an industry that constantly undergoes changes. Hence, new technology or procedures are available to adapt and head to the ultimate goal of profit optimization. An organization may not have the luxury of time to adapt to new changes, but it has to be done in the long-term plan. In summary, as change is constant in the working environment, leaders are always positioned to re-evaluate priorities to adapt, reinvent, and redesign solutions for organizations and employees to remain relevant in the job market.

\section{Acknowledgments}

This work was completed to fulfill the Doctor of Philosophy (Management) degree requirements by the Faculty of Economics and Business, University Malaysia Sarawak. The author appreciates the effort of editors and reviewers in improving the quality of this manuscript. Special appreciation to Dr. Hamrila Binti Abdul Latip (Supervisor), Dr. Dayang Affizzah Binti Awang Marikan (Co-supervisor), and Dr. Thavamaran Kanesan for feedback, comments, and words of encouragement.

\section{References}

Abd Rahman, A., Mohd Nazir, M. A., Haris, M. N., Abdul Ghafar, A. R., \& Yushunag, T. (2013). The Influence of Leadership Style on Job Satisfaction among Nurses. Asian Social Science, 172-178.

Anderson, J., \& Gerbing, D. (1988). Structural equation modeling in practice: A review and recommended two-step approach. Psychological Bulletin, 103(3), 411.

Apoi, A., \& Latip, H. (2019). The Impact of Transformational Leadership on Employee Reactions towards Individual Work Performance: A Conceptual Paper. International Journal of Academic Research in Business and Social Sciences, 9(8), 47-60. 
Awang, Z. (2014). A handbook on structural equation modeling. Bangi: MPWS Rich Resources. Awang, Z. (2015). Analyzing the moderating variables in a model: A handbook on SEM. Bangi: MPWS Publisher.

Awang, Z. (2015a). SEM Made Simple: A gentle approach to learning structural equation modeling. Bangi: MPWS Rich Publications.

Babalola, S. S. (2016). The Effect Of Leadership Style, Job Satisfaction And EmployeeSupervisor Relationship On Job Performance And Organizational Commitment. The Journal of Applied Business Research, 935-946.

Bagozzi, R., \& Yi, Y. (1988). On the evaluation of structural equation models. Journal of the Academy of Marketing Science, 16(1), 74-94.

Bartone, P., Krueger, G., \& Bartone, J. (2018). Individual Differences in Adaptability to Isolated, Confined, and Extreme Environments. Aerospace Medicine and Human Performance, 89(6), 536-546.

Bass, B. M. (1985). Leadership and Performance Beyond Expectations. New York: The Free Press.

Braun, S., Peus, C., Weisweiler, S., \& Frey, D. (2013). Transformational leadership, job satisfaction and team performance: A multilevel mediation model of trust. The Leadership Quarterly 24, 270-283.

Brian, K., \& Lewis, D. (2004). Exploring leadership preferences in multicultural workgroups: As Australian case study. The Leadership \& Organization Development Journal, 263-278.

Bryman, A. (2004). Combining Quantitative and Qualitative Research. In Social Research Methods, Alan Bryman (Ed.) (Second Edition ed.). Oxford: Oxford University Press.

Byrne, B. (2012). Structural Equation Modeling with Mplus: Basic Concepts, Applications and Programming. New York: Routledge.

Chan, D. (2014). Individual Adaptability to Changes at Work: New Directions in Research. New York: Routledge. Retrieved from https://worldcat.org/oclc/859383479

Cohen, J. (1988). Statistical power analysis: A computer program. New Jersey: Routledge.

Cooper, D., \& Schindler, P. (2008). Business Research Methods (10th Edition ed.). New York: McGraw-Hill/Irwin.

Dai, Y. D., Dai, Y. Y., Chen, K. Y., \& Wu, H. C. (2013). Transformational vs transactional leadership: which is better? A study on employees of international tourist hotels in Taipei City. International Journal of Contemporary Hospitality Management, 760-778.

Dg Kamisah, B. A., \& Syed, A. W. (2015). The relationship between culture and leadership styles preference among Malay-Brunei, Bajau and Kadazan-Dusun community in Sabah, Malaysia. Journal of Management Development, 1202-1210.

Dino, R. (2015). Crossing boundaries: Toward integrating creativity, innovation, and entrepreneurship research through practice. Psychology of Aesthetics, Creativity and the Arts, 9(2), 139-146.

Edwards, B. D., Bell, S. T., Arthur Jr., W., \& Decuir, A. D. (2008). Relationships between Facets of Job Satisfaction and Task and Contextual Performance. Applied Psychology, 441465.

Erkutlu, H. (2008). The impact of transformational leadership on organizational and leadership effectiveness: The Turkish case. Journal of Management Development, 708 - 726.

Evans, J. R., \& Lindsay, W. M. (2011). Managing for Quality and Performance Excellence. Mason, Oklahoma: South-Western Cengage Learning. 
Fornell, C., \& Larcker, D. F. (1981). Evaluating structural equation models with unobservable variables and measurement error. Journal of Marketing Research, 18(1), 39-50.

Griffith, J. (2004). Relation of principal transformational leadership to school staff job satisfaction, staff turnover and school performance. Journal of Educational Administration, 333-356.

Hair, J., Black, W., \& Babin, A. (2010). RE and Tatham, RL (2006), Multivariate Data Analysis. Upper Saddle River, NJ: Pearson Prentice Hall.

Hair, J., Black, W., Babin, B., \& Anderson, R. (2014). Multivariate Data Analysis (Seventh Edition ed.). United States of America: Pearson Education Limited.

Han, S. H., Seo, G., Yoon, S. W., \& Yoon, D. Y. (2016). Transformational leadership and knowledge sharing: Mediating roles of employee's empowerment, commitment, and citizenship behaviors. Journal of Workplace Learning, 130-149.

Hardy, C. A. (2014). Transformational leadership: a quasi-experimental study. Leadership and Organization Developmment Journal, 38-53.

Hooper, D., Coughlan, J., \& Mullen, M. (2008). Evaluating model fit: A synthesis of the structural equation modelling literature. 7th European Conference on Research Methodology for Business and Management Studies, 195-200.

Hoyle, R. (1995). Structural equation modeling: Concepts, issues, and applications. . Sage.

Hoyle, R. (2012). Handbook of structural equation modeling. New York: The Guilford Press.

Hua, J., Fan, J., Walker, A., Hou, N., Zheng, L., \& Debode, J. (2018). Examinations of the Role of Individual Adaptability in Cross-Cultural Adjustment. Journal of Career Assessment, 1-20.

Ingusci, E., Spagnoli, P., Zito, M., Colombo, L., \& Cortese, C. (2019). Seeking Challenges, Individual Adaptability and Career Growth in the Relationship between Workload and Contextual Performance: A Two-Wave Study. Sustainability, 1-13.

Ivey, G., \& Kline, T. J. (2010). Transformational and active transactional leadership in Canadian military. Leadership and Organization Development Journal, 246-262.

Janssen, O., \& Nico, W. (2004). Employees' goal orientations, the quality of leader-member exchange, and the outcomes of job performance and job satisfaction. Academy of Management Journal, 47(3), 368-384.

Jogulu, U., \& Ferkins, L. (2012). Leadership and culture in Asia: the case of Malaysia. Asia Pacific Business Review, 18(4), 531-549.

Judge, T. A., Thoresen, C. J., Bono, J. E., \& Patton, G. K. (2001). The Job Satisfaction-Job Performance Relationship: A Qualitative and Quantitative Review. Psychological Bulletin, 376-407.

Kashif, M., Samsi, S., Awang, Z., \& Mohamad, M. (2016). EXQ: Measurement of healthcare experience quality in Malaysian settings. International Journal of Pharmaceutical and Healthcare Marketing.

Katou, A. A. (2015). Transformational leadership and organisational performance: Three serially mediating mechanisms. Employee Reactions, 329-353.

Kinicki, A., \& Fugate, M. (2012). Organizational Behavior (5th ed.). New York: McGraw-Hill.

Kline, R. (2016). Principles and Practice of Structural Equation Modeling (Fourth Edition ed.). New York: The Guilford Press.

Koopmans, L., Bernaards, C. M., Hildebrandt, V. H., Schaufeli, W. B., Vet, H. C., \& Beek, A. J. (2011). Conceptual Frameworks of Individual Work Performance: A Systematic Review. American College of Occupational and Environmental Medicine, 53(8), 856866. doi:10.1097/JOM.0b013e318226a763 
Koopmans, L., Bernaards, C., Hildebrandt, V., Buuren, S. v., Beek, A. J., \& Vet, H. C. (2012). Development of an individual work performance questionnaire. International Journal of Productivity and Performance Management, 6-28.

Kreitner, R., \& Kinicki, A. (2013). Organizational behavior: tenth edition. New York, NY: McGraw-Hill Companies.

Kuo, H., Tseng, Y., \& Yang, Y. (2019). Promoting college student's learning motivation and creativity through a STEM interdisciplinary PBL human-computer interaction system design and development course. Thinking Skills and Creativity, 31, 1-10.

Lau, R. (2017). Expanding your skill set. BizHive Weekly, pp. 7-10.

Leana, C., Eileen, A., \& Iryna, S. (2009). Work Process and Quality of Care in Early Childhood Education: The Role of Job Crafting. Academy of Management Journal, 52, 1169-1192.

Ling, V. M., Lo, M. C., Sing, N. K. (2011). The influence of leadership styles on employees' job satisfaction in public sector organizations in Malaysia. International Journal of Business, Management and Social Sciences, 24-32.

MacCallum, R., Browne, M., \& Sugawara, H. (1996). Power analysis and determination of sample size for covariance structure modeling. Psychological Methods, 1(2), 130.

Md. Zabid, R. A., Sambasivan, M., \& Juliana, J. (2002). The influence of corporate culture and organisational commitment on performance. Journal of Management Development, 708-728.

Meyer, J. P., \& Allen, N. J. (1991). A three-component conceptualization of organizational commitment. Human Resource Management Review, 61-89.

Moirano, R., Sánchez, A. M., \& Štěpánek, L. (2020). Creative interdisciplinary collaboration: A systematic literature review. Thinking Skills and Creativity, 35. doi:https://doi.org/10.1016/j.tsc.2019.100626

Munchiri, M., Cooksey, R., \& Walumbwa, F. (2012). Transformational and social processes of leadership as predictors of organisational outcomes. Leadership \& Organization Development Journal, 662 - 683.

Nelson, D. L., \& Quick, J. C. (2013). Organizational Behavior: Science, the Real World and You (Eight Edition ed.). South-Western: Erin Joyner.

Nguni, S., Peter, S., \& Denessen, E. (2006). Transformational and transactional leadership effects on teachers' job satisfaction, organizational commitment, and organizational citizenship behavior in primary schools: The Tanzanian case. School Effectiveness and School Improvement, $145-177$.

Novak, T., \& Donna, L. (2009). The Fit of Thinking Style and Situation: New Measures of Situation-Specific Experiential and Rational Cognition. Journal of Consumer Research, 36, 56-72.

Oddane, T. (2015). The collective creativity of academics and practitioners in innovation projects. International Journal of Managing Projects in Business, 8(1), 33-57.

Organ, D. W. (1988). Organizational citizenship behavior: The good soldier syndrome. Lexington MA: Lexington Books.

Ozaralli, N. (2003). Effects of transformational leadership on empowerment and team effectiveness. Leadership and Orgabization Development Journal, 335-344.

Podsakoff, P. M., MacKenzie, S. B., Moorman, R. H., \& Fetter, R. (1990). Transformational leader behaviors and their effects on followers' trust in leader, satisfaction and organizational citizenship behaviors. Leadership Quarterly, 107-142.

Polyhart, R. E., \& Bliese, P. D. (2006). "Individual Adaptability (I-ADAPT) Theory: Conceptualizing the Antecedents, Consequences, and Measurement of Individual 
Differences in Adaptability". In Shawn Bruke, C., Pierce, L.G., \& Salas, E. (Ed.), Understanding Adaptability: A Prerequisite for Effective Performance within Complex Environments (Advances in Human Performance and Cognitive Engineering Research, Vol. 6) (pp. 3-39). Bingley: Emerald Group Publishing Limited.

Porter, L., Steers, R., Mowday, R., \& Boulian, P. (1974). Organizational Commitment, Job Satisfaction and Turnover among Psychiatric Technicians. Journal of Applied Psychology, 59(5), 603-609.

Robbins, S. P., \& Coulter, M. (2005). Management (8th ed.). Upper Saddle River, New Jersey: Pearson Prentice Hall.

Rotundo, M., \& Sackett, P. R. (2002). The Relative Importance of Task, Citizenship, and Counterproductive Performance to Global Ratings of Job Performance: A PolicyCapturing Approach. Journal of Applied Psychology, 66-80.

Salkind, N. (2006). Exploring Research (6th ed. ed.). Upper Saddle River, New Jersey: Pearson Education, Inc.

Sarros, J. C., \& Santora, J. C. (2001). The transformational-transactional leadership model in practice. Leadership and Organization Development Journal, 383-393.

Stachelek, M. (2018). Individual adaptability and performance in new environments: The relationships between individual adaptability and performance based off stress, personality and cognitive ability in a new environment. Michigan: ProQuest.

Steyrer, J., Schiffinger, M., \& Lang, R. (2008). Organizational commitment-A missing link between leadership behavior and organizational performance? Scandinavian Journal of Management, 364-374.

Tang, M., \& Werner, C. (2017). An interdisciplinary and intercultural approach to creativity and innovation: Evaluation of the EMCI ERASMUS intensive program. Thinking Skills and Creativity, 24, 268-278.

Vaughn, E. D. (2011). A Longitudinal Examination of Individual Adaptability as an Antecedent of Training and Transfer Outcomes. Auburn, Alabama: Auburn University.

Wang, H.-J., Demerouti, E., \& Le Blanc, P. (2017). Transformational leadership, adaptability, and job crafting: The moderating role of organizational identification. Journal of Vocational Behavior, 100, 185-195.

Xirasagar, S. (2008). Transformational, transactional and laissez-faire leadership among physician executives. Journal of Health Organization and Management, 599-613.

Zhang, X., \& Kathryn, M. (2010). Linking Empowering Leadership and Employee Creativity: The Influence of Psychological Empowerment, Intrinsic Motivation and Creative Process Engagement. Academy of Management Journal, 53, 107-128.

Zhou, M., \& Lin, W. (2016). Adaptability and Life Satisfaction: The Moderating Role of Social Support. Frontiers in Psychology, 7, 1-7.

Zorzie, M. (2012). Individual Adaptability: Testing A Model of Its Development and Outcomes. Michigan: Michigan State University. 